\title{
Characteristics of Female Nonagenarian Participants in an Observational Health Study
}

Pasco JA ${ }^{1,2,3^{*}}$, Holloway $\mathrm{KL}^{1}$ and Brennan $\mathrm{SL}^{1,2}$

${ }^{1}$ School of Medicine, Deakin University, Geelong, VIC, Australia

${ }^{2}$ NorthWest Academic Centre, Department of Medicine, The University of Melbourne, St Albans, VIC, Australia

${ }^{3}$ Division of Medicine, Barwon Health, Geelong, VIC, Australia

"Corresponding author: Julie A. Pasco, Epi-Centre for Healthy Ageing, IMPACT SRC, School of Medicine, Deakin University, PO Box 281, Geelong, Victoria 3220, Australia, Tel: +61 3 42153331; Fax: +61 3 42153491; E-mail: juliep@barwonhealth.org.au

Rec date: Aug 22, 2014; Acc date: Oct 29, 2014; Pub date: Oct 31, 2014

Copyright: (C) 2014 Pasco JA, et al. This is an open-access article distributed under the terms of the Creative Commons Attribution License, which permits unrestricted use, distribution, and reproduction in any medium, provided the original author and source are credited.

\begin{abstract}
Background: Inclusion of very elderly participants in health studies is limited, despite the increasing longevity in the population. We aimed to describe characteristics of female nonagenarians who had been retained for a decade in an ongoing, population-based cohort study.
\end{abstract}

Methods: This study describes 14 female nonagenarians who participated in the 10-year follow-up phase of the Geelong Osteoporosis Study. Their baseline characteristics, from a decade earlier, were compared with 109 fellow participants lost to follow-up.

Results: For nonagenarians at follow-up, mean BMI, relative appendicular mass and blood pressure were in the ideal ranges recommended for all adult ages, whereas mean BMD was in the osteopenic range for the hip and spine. Three $(21.4 \%)$ of the nonagenarian women were underweight, four $(28.6 \%)$ were overweight and one was obese; five (38.5\%) had hypertension, two (14.3\%) required assistance walking, nine (69.2\%) had osteoporosis and two $(15.4 \%)$ had low lean mass in the sarcopenic range. None of the women smoked or had fallen in the previous year, nine $(64.3 \%)$ used three or more prescription medications and five $(35.7 \%)$ used five or more. Comparisons of baseline data collected a decade earlier for the nonagenarians and their peers who were subsequently lost to followup, showed similarities in body habitus, falls, polypharmacy, education, marriage status, socioeconomic status and morbidity. However, the group lost to follow-up were more likely to have had osteoporosis and/or be hypertensive.

Conclusion: We present health-related data for nonagenarian participants of a prospective cohort study. While few differences were found between these participants and age-matched peers for baseline data collected a decade earlier, the nonagenarians who participated in the 10-year follow-up were less likely to have had osteoporosis or hypertension than their peers at recruitment. Further involvement of the very elderly in health research is warranted, since data for this age group are rare.

Keywords: Aged; Epidemiology; Evidence-based research; Population studies; Very elderly; Study participants; Nonagenarians

\section{Introduction}

Since our population is ageing, more people are living to very old age with improved health and functioning [1]. Between 1996 and 2006 in Australia, the number of individuals aged 90 years and over increased by $76.8 \%$, from 61,386 [2] to 108,538 [3]. Therefore it is timely to involve the very elderly in health studies in order to develop evidence upon which to base decision-making and health recommendations for this target population.

Data gathered from younger individuals are not necessarily generalisable to the very elderly. Nonagenarians engage in less physical activity and their daily activities differ from younger individuals [4]. Some sociodemographic factors commonly recognised as risk factors for mortality among younger elderly populations, are not necessarily associated with mortality among the very elderly [5] and unfounded concerns about adverse events may needlessly limit the use of interventions in this age group [6]. We aimed to describe characteristics of female nonagenarians who had been retained for a decade in an ongoing, population-based cohort study and compare them to age-matched participants on the basis of health-related factors collected a decade earlier for both groups.

\section{Materials and Methods}

\section{Subjects}

This observational study was set in south-eastern Australia, in a region described as the Barwon Statistical Division. The study utilised data from both baseline and the 10-year follow-up phase of the Geelong Osteoporosis Study (GOS). During the years 1993 and 1997, we recruited an age-stratified sample of 1494 women, aged 20-94 years, who had been selected at random from Commonwealth electoral rolls, with a participation rate of $77 \%$. From 1067 women who were available for the 10-year follow-up phase of the study, 881 participated. Details of recruitment and retention have been published elsewhere [7]. For this analysis, we characterise women who were aged 
in their nineties when they participated in the 10-year follow-up. One participant was two months short of her ninetieth birthday and has been included in the group of nonagenarians. The oldest participant was aged 93 years. Between baseline assessment and 10 -year follow-up, $83(67.5 \%)$ of the women died and a further 26 were lost to follow-up. In order to gauge whether the 14 very elderly women who were retained in the study and participated in the 10-year follow-up differed from their peers who were lost to follow-up, we compared their characteristics when they were all assessed at baseline, a decade earlier. The study was approved by the Human Research Ethics Committee at Barwon Health. All participants gave informed, written consent.

\section{Measures}

Standing height was measured to the nearest $0.1 \mathrm{~cm}$ using a wallmounted stadiometer, weight was measured to the nearest $0.1 \mathrm{~kg}$ using electronic scales and body mass index (BMI) was calculated as weight/ height ${ }^{2}\left(\mathrm{~kg} / \mathrm{m}^{2}\right)$. Subjects were categorised as underweight if $\mathrm{BMI}<18.5$ $\mathrm{kg} / \mathrm{m}^{2}$, overweight if BMI was in the range $25.0-29.9 \mathrm{~kg} / \mathrm{m}^{2}$, and obese if $\mathrm{BMI}>30 \mathrm{~kg} / \mathrm{m}^{2}$ [8]. Dual energy $\mathrm{x}$-ray absorptiometry (Lunar DPXL, Madison, WI, USA) provided measures of areal bone mineral density (BMD) at the spine (L2-4, anterior-posterior projection), hip (femoral neck), whole body, ultradistal forearm and mid-forearm. Short-term precision in vivo was $0.6 \%, 1.6 \%, 0.4 \%, 2.1 \%$ and $1.1 \%$, respectively. Osteoporosis and osteopenia referred to BMD deficits at the spine and/or hip. Cut-off BMD values at the spine and hip were calculated using Australian reference ranges for women [9] corresponding to osteopenia (1.0-2.5 SD below the young reference mean) and osteoporosis ( $>2.5 \mathrm{SD}$ below the young reference mean). Whole body scans also provided measures of lean tissue and body fat mass. For participants who had prostheses, plates, screws, pace-makers or non-removable jewellery on one side of the body, lean tissue and body fat values of the unaffected side were substituted; those with bilateral devices or missing scans were excluded. Appendicular lean mass $(\mathrm{kg})$ was determined by summing lean mass measures for the arms and legs and this was converted to relative appendicular lean mass by dividing by the square of height in metres $\left(\mathrm{kg} / \mathrm{m}^{2}\right)$. Sarcopenia was identified if relative appendicular lean mass $<2 \mathrm{SD}$ below the young normal mean [10]. The percentage skeletal muscle index (SMI $\%)$ and percentage body fat mass $(\% \mathrm{BF})$ were also calculated by expressing lean and body fat masses as percentages of body weight. One of the 14 women was scanned at the forearm only and so did not provide measures of whole body BMD, lean tissue or body fat mass. Blood pressure was measured with the subject seated using a digital meter (Model UA-751). Hypertension was classified as systolic $\mathrm{BP}>140 \mathrm{mmHg}$ and/or diastolic BP $>90 \mathrm{mmHg}$. Missing data: $\mathrm{n}=17$ blood pressure; $\mathrm{n}=1$ spine $\mathrm{BMD} ; \mathrm{n}=3$ hip $\mathrm{BMD}, \mathrm{n}=18$ whole body scans; $\mathrm{n}=9$ forearm BMD.

Concurrent lifestyle factors (including smoking, use of medications, exposure to diseases), falls, mobility/physical activity, marriage and education were documented by questionnaire. Mobility was classified as 'active' if exercise was performed regularly and 'sedentary or limited' if they reported the following: little walking outside home, able to prepare meals and perform light household tasks and 'required assistance with walking' if they were inactive or chair/bedridden. Women who reported not falling or rarely doing so during the previous 12 months were categorised as non-fallers, whereas those with few, several or regular falls were classified as fallers. Education was categorised as having at least completed secondary school in contrast to those who had not reached this level of education. Polypharmacy was identified in two categories: if three or more (3+) and five or more (5+) prescription medications were used regularly. Missing data: $\mathrm{n}=1$ smoking status; $\mathrm{n}=1$ marriage status; $\mathrm{n}=5$ education; $\mathrm{n}=3$ falls; $\mathrm{n}=2$ medications. Socioeconomic status was ascertained using Socio-Economic Index For Areas scores based on census data from the Australian Bureau of Statistics (1996). These data were used to derive an Index of Relative Social Disadvantage (IRSD) that was categorised into five groups, according to quintiles of IRSD for the study region and subsequently collapsed into three groups low (most disadvantaged, quintiles 1 and 2), medium (quintile 3) and high (least disadvantaged (quintiles 4 and 5).

\section{Statistical analysis}

Differences in baseline characteristics between women who did and did not return for 10-year follow-up assessments were identified using two-sample t-tests for parametric continuous data, Mann-Whitney test for non-parametric data and chi-squared test or Fisher's exact test for categorical data. All statistical analyses were performed using Minitab (version 16; Minitab, State College, PA, USA).

\section{Results}

\section{Characteristics of nonagenarians who participated in the 10- year follow-up}

Subject characteristics for nonagenarian women at 10-year followup are shown in Table 1. Although mean BMI for the group was in the ideal weight range, 3 (21.4\%) were underweight and 4 (28.6\%) were overweight; only one was obese. Two (15.4\%) had BMD in the normal range for hip and/or spine, 2 (15.4\%) in the osteopenic range and 9 $(69.2 \%)$ in the osteoporotic range. The overall mean value for relative appendicular lean mass was above the threshold for sarcopenia, however, 2 (15.4\%) of the women were below this threshold; none had both sarcopenia and obesity. Mean values for systolic and diastolic blood pressure did not exceed thresholds for hypertension; however, 5 (38.5\%) were classified as hypertensive. One participant reported high levels of physical activity, most reported being sedentary or having limited mobility and two were inactive or bed/chair ridden and required assistance with walking. There were no current smokers among the very elderly women, although five (35.7\%) were past smokers, and none had fallen in the previous year; over half $(64.3 \%)$ regularly used $3+$ prescription medications and one-third $(35.7 \%)$ used $5+$.

\begin{tabular}{|l|l|}
\hline & $\begin{array}{l}\text { Nonagenarians } \\
\mathrm{n}=14\end{array}$ \\
\hline Age (years) & $91.5( \pm 1.0)$ \\
\hline Weight $(\mathrm{kg})$ & $57.1( \pm 12.7)$ \\
\hline Height $(\mathrm{cm})$ & $155.5( \pm 6.9)$ \\
\hline Body mass index $\left(\mathrm{kg} / \mathrm{m}^{2}\right)$ & $23.5( \pm 4.6)$ \\
\hline Bone mineral density $\left(\mathrm{g} / \mathrm{cm}^{2}\right)$ & \\
\hline spine & $1.012( \pm 0.210)$ \\
\hline hip & $0.682( \pm 0.161)$ \\
\hline whole body & $0.952( \pm 0.101)$ \\
\hline ultra-distal forearm & $0.234( \pm 0.065)$ \\
\hline
\end{tabular}


Citation: Pasco JA, Holloway KL, Brennan SL (2014) Characteristics of Female Nonagenarian Participants in an Observational Health Study. J

Page 3 of 5

\begin{tabular}{|l|l|}
\hline mid-forearm & $0.529( \pm 0.089)$ \\
\hline Lean mass $(\mathrm{kg})$ & $34.3( \pm 4.8)$ \\
\hline Skeletal muscle index $(\%)$ & $62.6( \pm 9.1)$ \\
\hline Appendicular lean mass $(\mathrm{kg})$ & $14.7( \pm 2.5)$ \\
\hline Relative appendicular lean mass $\left(\mathrm{kg} / \mathrm{m}^{2}\right)$ & $6.0( \pm 0.8)$ \\
\hline Fat mass $(\mathrm{kg})$ & $17.5( \pm 8.2)$ \\
\hline \% Fat mass & $29.8( \pm 8.3)$ \\
\hline Blood pressure $(\mathrm{mmHg})$ & \\
\hline Systolic & $137( \pm 17)$ \\
\hline Diastolic & $70( \pm 14)$ \\
\hline Smokers & \\
\hline current & 0 \\
\hline past & $5(35.7 \%)$ \\
\hline Mobility & \\
\hline active & $1(7.1 \%)$ \\
\hline sedentary/limited & $11(78.6 \%)$ \\
\hline dependent & $2(14.3 \%)$ \\
\hline Fallers & 0 \\
\hline Polypharmacy & $9(64.3 \%)$ \\
\hline 3 or more medications & $5(35.7 \%)$ \\
\hline 5 or more medications & \\
\hline One participant was scanned only at the forearm sites. & \\
\hline
\end{tabular}

Table 1: Baseline characteristics for the nonagenarians who participated in the 10-year follow-up phase of the Geelong Osteoporosis Study, Data are shown as mean $( \pm \mathrm{SD})$ or $\mathrm{n}(\%)$.

\section{Baseline characteristics of 10-year follow-up participants compared to those lost to follow-up}

Comparisons of characteristics at baseline between those who participated in the 10-year follow-up phase and those who were lost to follow-up are presented in Table 2. There were no differences detected between the groups in terms of mean age, weight, BMI, lean mass, fat mass, or in the proportions related to falls, polypharmacy, marriage status, education, socioeconomic status, or presence of cardiovascular, endocrinological, respiratory or gastrointestinal disease/disorders. However, compared with those lost to follow-up a decade later, baseline data showed that the retained group was less likely to have osteoporosis $(28.6 \%$ vs $55.1 \%, \mathrm{p}=0.059)$ and less likely to be hypertensive ( $30.8 \%$ vs $61.3 \%, \mathrm{p}=0.037$ ). Among the retained group, 3 (21.4\%) were physically active, most $(\mathrm{n}=11,78.6 \%)$ were sedentary or had limited mobility, and none was dependent on assistance for walking. Among those lost to follow-up, 9 (8.3\%) were active, 94 $(87.0 \%)$ were sedentary or had limited mobility and 5 (4.6\% required assistance for walking). Although 7 (50.0\%) of the retained group were overweight, $46(42.2 \%)$ of those lost to follow-up were overweight; proportions classified as obese were $7.1 \%$ vs $17.4 \%$, respectively, but

these differences were not significant $(\mathrm{p}=0.606)$. One of the retained group was sarcopenic $(9.1 \%)$ compared to six $(6.4 \%)$ of those lost to follow-up, but this difference was not significant either $(\mathrm{p}=0.550)$.

\begin{tabular}{|c|c|c|c|}
\hline & $\begin{array}{l}\text { Participants } \\
n=14\end{array}$ & $\begin{array}{l}\text { Lost to follow- } \\
\text { up } \\
n=109\end{array}$ & $\begin{array}{l}\mathrm{p}- \\
\text { value }\end{array}$ \\
\hline Age (years) & $82.5( \pm 1.3)$ & $82.9( \pm 1.4)$ & 0.303 \\
\hline Weight (kg) & $61.7( \pm 10.4)$ & $61.0( \pm 9.8)$ & 0.800 \\
\hline Height $(\mathrm{cm})$ & $157.6( \pm 5.8)$ & $153.7( \pm 6.0)$ & 0.022 \\
\hline Body mass index $\left(\mathrm{kg} / \mathrm{m}^{2}\right)$ & $24.8( \pm 3.4)$ & $25.8( \pm 3.8)$ & 0.321 \\
\hline \multicolumn{4}{|l|}{$\operatorname{BMD}\left(\mathrm{g} / \mathrm{cm}^{2}\right)$} \\
\hline PA-spine & $\begin{array}{l}1.064 \\
( \pm 0.221)\end{array}$ & $0.985( \pm 0.206)$ & 0.183 \\
\hline Femoral neck & $\begin{array}{l}0.775 \\
( \pm 0.159)\end{array}$ & $0.708( \pm 0.113)$ & 0.057 \\
\hline Whole body & $\begin{array}{l}1.009 \\
( \pm 0.106)\end{array}$ & $0.963( \pm 0.100)$ & 0.122 \\
\hline Ultra-distal forearm & $\begin{array}{l}0.240 \\
( \pm 0.059)\end{array}$ & $0.222( \pm 0.049)$ & 0.227 \\
\hline Mid-forearm & $\begin{array}{l}0.538 \\
( \pm 0.071)\end{array}$ & $0.498( \pm 0.075)$ & 0.072 \\
\hline Lean mass $(\mathrm{kg})$ & $34.8( \pm 4.4)$ & $34.2( \pm 3.8)$ & 0.655 \\
\hline Skeletal muscle index (\%) & $58.4( \pm 7.6)$ & $57.9( \pm 8.1)$ & 0.846 \\
\hline Appendicular lean mass $(\mathrm{kg})$ & $15.1( \pm 2.2)$ & $14.6( \pm 1.9)$ & 0.422 \\
\hline $\begin{array}{l}\text { Relative appendicular lean mass } \\
\left(\mathrm{kg} / \mathrm{m}^{2}\right)\end{array}$ & $6.1( \pm 0.7)$ & $6.2( \pm 0.7)$ & 0.626 \\
\hline Fat mass $(\mathrm{kg})$ & $22.9( \pm 7.3)$ & $22.9( \pm 7.3)$ & 0.998 \\
\hline$\%$ body fat mass & $37.4( \pm 7.7)$ & $37.4( \pm 8.2)$ & 0.982 \\
\hline \multicolumn{4}{|l|}{ Blood pressure (mmHg) } \\
\hline Systolic & $136( \pm 19)$ & $146( \pm 26)$ & 0.160 \\
\hline Diastolic & $77( \pm 12)$ & $82( \pm 16)$ & 0.231 \\
\hline Current smokers & 0 & $2(1.8 \%)$ & - \\
\hline Fallers & $5(35.7 \%)$ & $31(29.3 \%)$ & 0.620 \\
\hline \multicolumn{4}{|l|}{ Polypharmacy } \\
\hline 3 or more medications & $9(64.3 \%)$ & $62(59.1 \%)$ & 0.706 \\
\hline 5 or more medications & $3(21.4 \%)$ & $30(28.6 \%)$ & 0.755 \\
\hline \multicolumn{4}{|l|}{ Diseases/disorders } \\
\hline cardiovascular & $8(57.1 \%)$ & $71(65.1 \%)$ & 0.561 \\
\hline endocrinological & $3(21.4 \%)$ & $20(18.4 \%)$ & 0.725 \\
\hline respiratory & $4(28.6 \%)$ & $17(15.6 \%)$ & 0.257 \\
\hline gastrointestinal & $4(28.6 \%)$ & $31(28.4 \%)$ & 1 \\
\hline Married & $3(21.4 \%)$ & $31(28.7 \%)$ & 0.755 \\
\hline
\end{tabular}




\begin{tabular}{|l|l|l|l|}
\hline $\begin{array}{l}\text { Completed secondary school (or } \\
\text { above) }\end{array}$ & $4(30.8 \%)$ & $23(21.9 \%)$ & 0.491 \\
\hline Socioeconomic status & & & 0.915 \\
\hline low & $5(35.7 \%)$ & $45(41.3 \%)$ & \\
\hline medium & $4(28.6 \%)$ & $27(24.8 \%)$ & \\
\hline high & $5(35.7 \%)$ & $37(33.9 \%)$ & \\
\hline
\end{tabular}

Missing data: $n=17$ no blood pressure measures; $n=1$ no smoking status; $n=3$ falls; $n=2$ medications; $n=1$ marriage status; $n=5$ education; $n=1$ spine BMD; $\mathrm{n}=3$ hip $\mathrm{BMD}, \mathrm{n}=18$ whole body scans; $\mathrm{n}=9$ forearm BMD.

Table 2: Comparison of baseline characteristics for participants of the 10 -year follow-up and those lost to follow-up. Data are shown as mean $( \pm \mathrm{SD})$ or $\mathrm{n}(\%)$.

\section{Discussion}

None of the nonagenarians was free of disease and most had BMI in the ideal range, a few were underweight and only one was obese. The mean values for BMI were lower than previously reported values for women aged $70-79$ years $\left(27.9 \mathrm{~kg} / \mathrm{m}^{2}\right)$ and $80+$ years $\left(26.4 \mathrm{~kg} / \mathrm{m}^{2}\right)$; similarly, mean \%BF was lower than for ages $70-79$ years $(40.9 \%)$ and $80+$ years $(38.4 \%)$ [11]. Only two had low lean mass reflecting agerelated muscle loss and none had sarcopenic obesity. Mean values for appendicular lean mass were similar to mean values previously reported for women aged 70-79 years and 80+ years (14.9 and $14.7 \mathrm{~kg}$, respectively), but mean values for relative appendicular lean mass were lower than those reported for the younger age groups (6.6 and 6.5 $\mathrm{kg} / \mathrm{m}^{2}$, respectively) [10]. Deficits in bone density were common and most had osteoporosis. The proportion with osteoporosis was somewhat higher than reported values for women aged 70-74 years (32.6\%), 75-79 years (42.7\%) and $80+$ years (51.0\%) [12]; this pattern is concordant with the recognised age-related decline in BMD [9] Approximately one-third of the women was identified as hypertensive, most were sedentary or had limited mobility, yet none had sustained a fall in the previous year. The finding that none of these very elderly women had fallen was surprising because it has been reported that approximately one-third of community-dwelling people over the age of 75 years experiences a fall each year [13]. These new data contribute to the health profiles of very elderly women but they raise questions about how representative they are of their peers.

Several studies have described the characteristics of nonagenarians in different populations. One study described the health of 192 Finnish nonagenarian women. [14]. Average height was $157.5 \mathrm{~cm}$ and weight $61.1 \mathrm{~kg}$, which is slightly higher than the values obtained in our study $(155.5 \mathrm{~cm}$ and $57.1 \mathrm{~kg})$. Weight categories for the Finnish sample revealed that $1.6 \%$ were underweight, $58.8 \%$ were of ideal weight, $32.3 \%$ were overweight and $7.3 \%$ were obese. Our results were $21.4 \%$ underweight, $42.9 \%$ ideal weight, $28.6 \%$ overweight and $7.1 \%$ obese; a larger proportion of our participants was underweight than in the Finnish cohort. Of the 192 Finnish participants, 3.1\% were current or former smokers and, although none of those in our study was a current smoker, one-third were former smokers. Another study of 446 Canadian nonagenarian females reported weight category results more similar to our study [15]; $11.5 \%$ underweight, $57.9 \%$ ideal and $30.5 \%$ overweight or obese. However, in this study, a comparable proportion to that found in our study was current or former smokers; $36.2 \%$. Mobility was similar; $88.8 \%$ of the Canadian nonagenarians had limited or dependent mobility and the comparative value from our study was $92.9 \%$. Hypertension in the Canadian women was also similar to our result; 46.55 and $38.5 \%$, respectively.

We compared the characteristics of our nonagenarian women with their peers (all at baseline) using data collected a decade earlier, at recruitment. A comparison of the retained group with those lost to follow suggests many similarities, yet there were some differences. Indices of body composition were largely similar, with the exception that those lost to follow-up tended to have poorer bone health. Our data suggest no differences in lean mass; loss of lean mass is considered a marker of frailty and underpins loss of mobility and independence [16]. It is interesting that those lost to follow-up tended to be less active and had a greater likelihood of being dependent and requiring assistance with walking. No difference in falls was recorded.

The limitations of using a 'one-size-fits-all' BMI range for advocating ideal weight for adults across the age spectrum are well recognised. The BMI generally underestimates adiposity in the elderly who exhibit age-related losses of musculoskeletal tissue [17]. Despite the likely under-estimation of the obese group, there was a greater proportion of women with $\mathrm{BMI}>30.0 \mathrm{~kg} / \mathrm{m}^{2}$ in the group lost to follow-up. Recent research suggests that a BMI of $27.5 \mathrm{~kg} / \mathrm{m}^{2}$ (currently considered overweight) is associated with the lowest mortality risk among people aged 65 years and older [18]. While it seems likely that carrying some extra weight could be suggested for better health among the very elderly, further research is required to refine recommendations for this age group.

We did not detect any difference in marriage status, education or socioeconomic status between the women who were retained in the study and those lost to follow-up. These findings are in contrast to other studies that report that being married and having higher socioeconomic status and a higher level of education are associated with what can be regarded as successful ageing $[19,20]$. The minority of our sample was married or had completed secondary school and we did not have enough power to further investigate whether being widowed or having tertiary education was associated with retention in our cohort study. Furthermore, whether participating in a health study can be considered a marker of healthy ageing is not clear.

The strength of the study is that participants were selected at random from electoral rolls and so they were not selected on the basis of health or disease. However, inability to provide informed consent was an exclusion criterion and participants were required to attend the research centre for assessment. Consequently, elderly study participants were likely to be more robust than individuals who did not participate. We have previously reported that for women, the most common reasons for non-participation in our study were personal reason/disinterest, frailty/inability to cope with the study, time constraints, and reluctance over medical testing [21]; unfortunately, we were not able to stratify those reasons by age. The women who were lost to follow-up appeared to be equivalent to those retained in the study for a decade in terms of polypharmacy and morbidity. We cannot exclude the possibility that elderly women who were recruited into the baseline phase were relatively healthy compared to their peers from the underlying population. Another limitation of our study is that we relied on some self-reported data. A recent US study reported that successively older study participants showed age-related divergence (typically more favourably) from their peers when selfreporting health [22]. However, their oldest participant was aged 80 years and it remains unclear whether this pattern would extend to the very elderly. Where practical, we conducted clinical assessments rather than rely on self-reports. As this study focused on female participants 
our findings may not be generalisable to men. However, in the male arm of the Geelong Osteoporosis Study, which recruited participants between 2001 and 2006, there were nine nonagenarians among a group of 200 men aged 80 years and older [7]. Characteristics of the very elderly men recruited, retained and lost to follow-up will determined when the 10-year follow-up phase of the study has been completed.

In conclusion, we present health-related data about very elderly participants in a large population-based cohort study. While there were few differences between these participants and age-matched peers for data collected a decade earlier, the women who stayed in the study were healthier at recruitment in terms of osteoporosis and hypertension. We acknowledge their involvement in our study and hope there will be further research involving the very elderly.

\section{Acknowledgements}

The authors acknowledge the women who participated in the study.

Author Contributions: All authors contributed to the interpretation of data, the writing and critical appraisal of the manuscript and approval of the final version for submission.

The study was funded by the Victorian Health Promotion Foundation and the National Health and Medical Research Council (NHMRC) of Australia, but they played no part in the design or conduct of the study; collection, management, analysis, and interpretation of the data; or in preparation, review, or approval of the manuscript. SLB is supported by NHMRC Early Career Fellowship (1012472).

\section{References}

1. Christensen K, Thinggaard M, Oksuzyan A, Steenstrup T, AndersenRanberg K, et al. (2013) Physical and cognitive functioning of people older than 90 years: a comparison of two Danish cohorts born 10 years apart. Lancet 382: 1507-1513.

2. Australian Bureau of Statistics, 1996 Census. Catalogue No. 2020.0. Commonwealth of Australia, 1997.

3. Australian Bureau of Statistics, 2006 Census. Catalogue No. 2001.0. Commonwealth of Australia, 2007.

4. Horgas AL, Wilms HU, Baltes MM (1998) Daily life in very old age: everyday activities as expression of successful living. Gerontologist 38: 556-568.

5. Nybo H, Petersen HC, Gaist D, Jeune B, Andersen K, et al. (2003) Predictors of mortality in 2,249 nonagenarians--the Danish 1905-Cohort Survey. J Am Geriatr Soc 51: 1365-1373.

6. Fisher AA, McLean AJ, Davis MW, Le Couteur DG (2003) A multicenter, case-control study of the effects of antihypertensive therapy on orthostatic hypotension, postprandial hypotension, and falls in octo- and nonagenarians in residential care facilities. Curr Ther Res Clin Exp 64: 206-214.
7. Pasco JA1, Nicholson GC, Kotowicz MA (2012) Cohort profile: Geelong Osteoporosis Study. Int J Epidemiol 41: 1565-1575.

8. World Health Organization, Obesity: preventing and managing the global epidemic. Report of a WHO Consultation on Obesity. Geneva, 3-5 June 1997. Geneva: WHO, 1998.

9. Henry MJ, Pasco JA, Pocock NA, Nicholson GC, Kotowicz MA (2004) Reference ranges for bone densitometers adopted Australia-wide: Geelong osteoporosis study. Australas Radiol 48: 473-475.

10. Gould H, Brennan SL, Kotowicz MA, Nicholson GC, Pasco JA (2014) Total and appendicular lean mass reference ranges for Australian men and women: the Geelong osteoporosis study. Calcif Tissue Int 94: 363-372.

11. Pasco JA, Holloway KL, Dobbins AG, Kotowicz MA, Williams LJ, Brennan SL (2014) Body mass index and measures of body fat for defining obesity and underweight: a cross-sectional, population-based study. BMC Obesity 1: 9.

12. Henry MJ, Pasco JA, Nicholson GC, Kotowicz MA (2011) Prevalence of osteoporosis in Australian men and women: Geelong Osteoporosis Study. Med J Aust 195: 321-322.

13. Tinetti ME, Speechley M, Ginter SF (1988) Risk factors for falls among elderly persons living in the community. N Engl J Med 319: 1701-1707.

14. Lisko I, Tiainen K, Stenholm S, Luukkaala T, Hervonen A, et al. (2011) Body mass index, waist circumference, and waist-to-hip ratio as predictors of mortality in nonagenarians: the Vitality $90+$ Study. J Gerontol A Biol Sci Med Sci 66: 1244-1250.

15. Wister AV, Wanless D (2007) A health profile of community-living nonagenarians in Canada. Can J Aging 26: 1-18.

16. Janssen I, Heymsfield SB, Ross R (2002) Low relative skeletal muscle mass (sarcopenia) in older persons is associated with functional impairment and physical disability. J Am Geriatr Soc 50: 889-896.

17. Pasco JA, Nicholson GC, Brennan SL, Kotowicz MA (2012) Prevalence of obesity and the relationship between the body mass index and body fat: cross-sectional, population-based data. PLoS One 7: e29580.

18. Winter JE, MacInnis RJ, Wattanapenpaiboon N, Nowson CA (2014) BMI and all-cause mortality in older adults: a meta-analysis. Am J Clin Nutr 99: 875-890.

19. McLaughlin SJ, Connell CM, Heeringa SG, Li LW, Roberts JS (2010) Successful aging in the United States: prevalence estimates from a national sample of older adults. J Gerontol B Psychol Sci Soc Sci 65B: 216-226.

20. Nosraty L, Sarkeala T, Hervonen A, Jylhä M (2012) Is there successful aging for nonagenarians? The vitality $90+$ study. J Aging Res 2012: 868797.

21. Markanday S, Brennan SL, Gould H, Pasco JA (2013) Sex-differences in reasons for non-participation at recruitment: Geelong Osteoporosis Study. BMC Res Notes 6: 104.

22. Golomb BA, Chan VT, Evans MA, Koperski S, White HL, et al. (2014) The older the better: are elderly study participants more nonrepresentative? A cross-sectional analysis of clinical trial and observational study samples. BMJ Open 2: e000833. 